\title{
A comparison of techniques for determining prenatal sex from liquor amnii
}

\author{
B. V. LEWIS AND P. A. CHAPMAN
}

From the Division of Obstetrics and Gynaecology and Pathology, Maternity Unit, Watford General Hospital

SYNOPSIS The cellular content of amniotic fluid is primarily composed of desquamated squamous cells. Depending on their site of origin and maturation, the staining characteristics of the nuclei and cytoplasm differ. Prenatal foetal sex was determined by comparing the proportion of anucleate pyknotic nuclei to vesicular nuclei using Papanicolaou's stain and the proportion of red cells to blue cells using Shorr's stain.

Both techniques allow an accurate assessment of prenatal sex to be made after 30 week's gestation. There is a close correlation between the two methods.

Rosa and Fanard (1951) described a cytological method of determining foetal sex from the staining characteristics of cytoplasm in cells found in liquor amnii. Huisjes (1968) and Arendzen and Huisjes (1971) used the Harris-Shorr method of staining to confirm the findings of Rosa and Fanard, and concluded that a large proportion of the blue staining cells which are present in liquor near term were derived from vaginal epithelium. Other blue staining cells found in the liquor were thought to arise from the foetal mouth and urinary system and were therefore common to both male and female foetuses. Bennett, Morris, and Davey (1972) also found that the colour characteristics of foetal cells desquamated into the liquor amnii and stained by the Shorr method could be used to predict sex. Occasional discrepancies, however, were noted with this method.

In an attempt to increase the accuracy of prenatal sex determination two methods were employed and the foetal sex was independently predicted.

One method compared the number of cyanophilic cells with eosinophilic cells and the other the proportion of anucleate/pyknotic squames to intermediate squames. The results of the two methods were compared and it was found that a rapid prenatal diagnosis of foetal sex could be made with $100 \%$ accuracy.

\section{Materials and Methods}

Samples of liquor amnii were collected from 66

Received for publication 4 March 1974. patients after the 32nd week of gestation. The samples were collected at: (a) transabdominal amniocentesis in patients with Rhesus isoimmunization, (b) surgical induction of labour using a Drew Smythe catheter, the usual indication being preeclampsia, $(c)$ in spontaneous premature labour using a Drew Smythe catheter during sterile vaginal examination.

The pregnancies were otherwise normal and the length of gestation was accurately known.

As soon as possible after collection each sample of liquor was centrifuged at $\mathbf{2 0 0 0} \mathrm{rpm}$ for two minutes, and the deposit smeared onto clean glass slides. Fixation was in equal parts alcohol/ether for at least 30 minutes.

Shorr's stain was used on the smears for eosinophilic/cyanophilic ratio counts. Since only the cytoplasm of the cells was being studied there seemed no point in using a nuclear stain (Harris's haematoxylin). Duplicate smears where nuclear detail was being studied were stained by the routine Papanicolaou method. The following cells were observed and identified in the stained preparations.

ANUCLEATE SQUAMOUS CELLS

These are thin angular plaques of cytoplasm staining pink or blue ranging from 30 to $60 \mu$ in diameter (fig 1).

NUCLEATE SQUAMOUS CELLS

Large, flat cells with angular contours staining pink or blue range from 35 to $60 \mu$ in diameter and have either a pyknotic (ink spot) nucleus (fig 2a) or a 639 


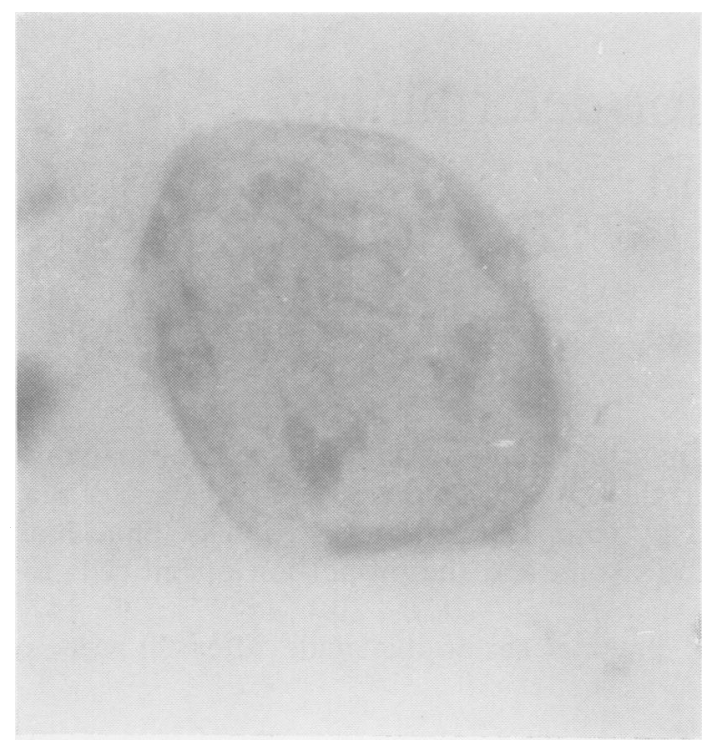

Fig 1 Anucleate squamous cell (Papanicolaou $\times 600$ )

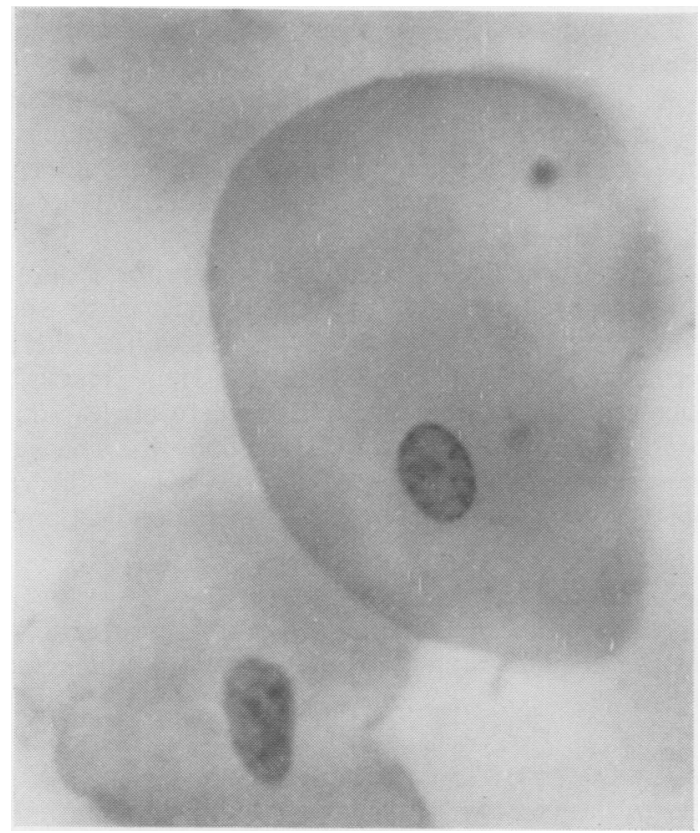

Fig 3 Intermediate cells (Papanicolaou $\times$ 600)

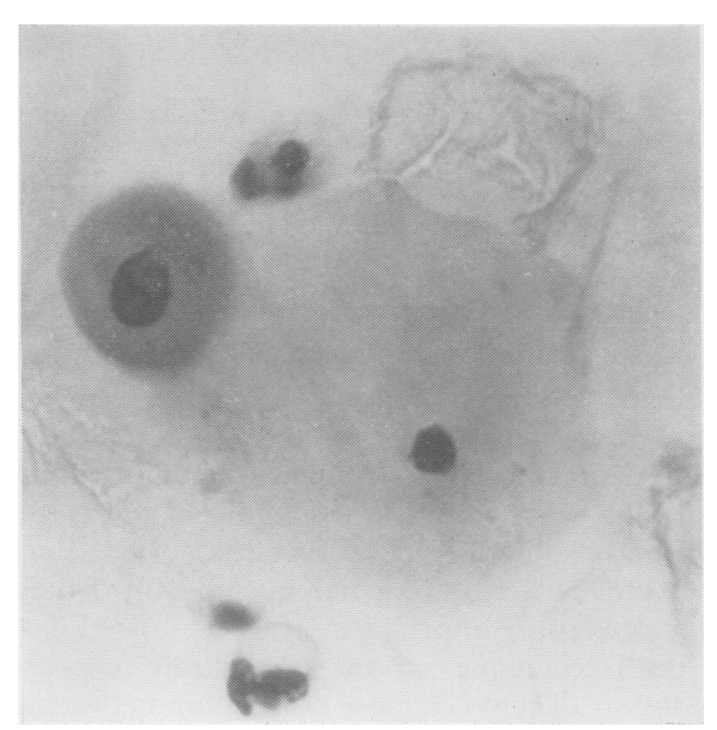

Figs $2 \mathrm{a}$ and $2 \mathrm{~b}$ Squamous cell and parabasal cell (Papanicolaou $\times 600)$

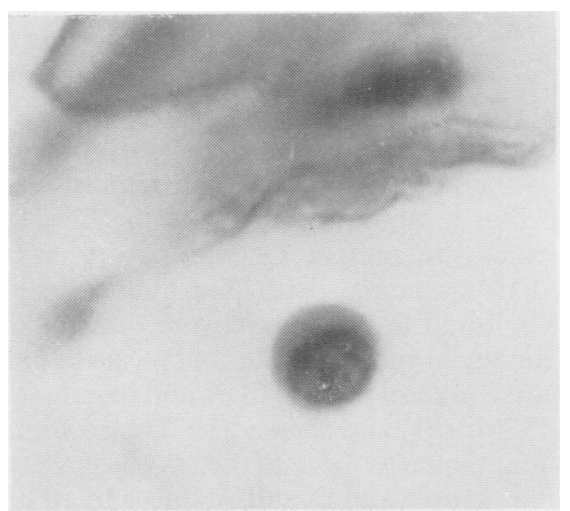

Fig 4 Transitional cell (Papanicolaou $\times 600$ )

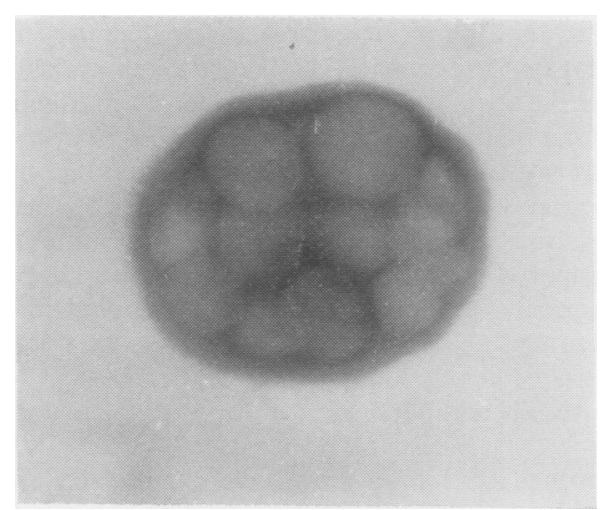

Fig 5 Amnion cell (Papanicolaou $\times 600$ ) 
vesicular (salt and pepper) nucleus (fig 3).

PARABASAL CELLS

These are round cells, 20 to $40 \mu$ in diameter, with a vesicular nucleus and blue staining cytoplasm (fig 2b).

\section{TRANSITIONAL CELLS}

Transitional cells, $10-12 \mu$ in diameter, have a coarse hyperchromatic nucleus and a little pale blue cytoplasm and resemble single endometrial cells (fig 4).

\section{AMNION CELLS}

Such cells are round or goblet in shape with a thick basophilic cytoplasm containing a large vacuole or multiple small vacuoles. The average diameter is $30 \mu$ with a vesicular nucleus (fig 5).

To determine the sites of origin of these cells smears were made from the vagina, vulva, skin surfaces, buccal cavity, urines, of both boy and girl neonates, umbilical cord and amnion (fig 6).

It was apparent that the foetal vagina and vulva were the main source of intermediate squames with vesicular nuclei, although they were found in other sites-groin, axilla, buccal cavity, lower urinary tract, and umbilical cord. At least 300 cells were counted on each slide examined, the parabasal and transitional cells from the urinary tract and the multivacuolated cells from the amnion being disregarded.

\section{Results}

In 23 of 24 patients subsequently delivered of a male foetus the percentage of blue-staining cells in the liquor did not exceed $20 \%$ (fig 7 ). The one exception had $31 \%$ cyanophilic cells. In all 42 patients subsequently delivered of a female foetus the percentage

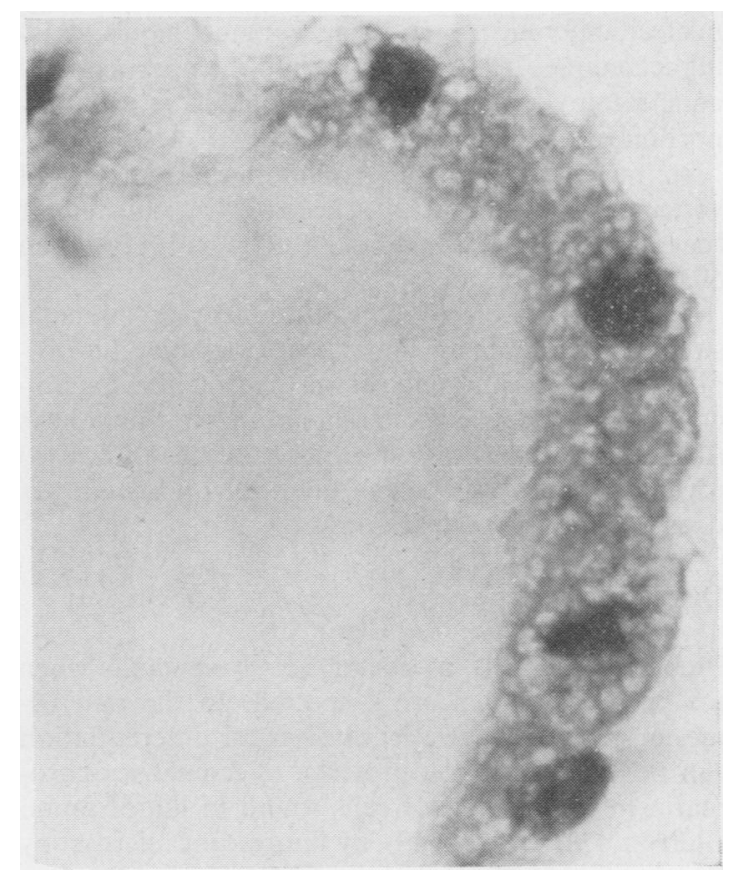

Fig 6 Section of amnion at 38 weeks' gestation showing source of multivacuolated cells $(H \& E \times 600)$

of blue-staining cells always exceeded $28 \%$, and in only two patients did the percentage of blue-staining cells fall below $40 \%(38 \%$ and $28 \%$ ). In liquor from 42 women with female foetuses there were more than $50 \%$ blue-staining cells in $80 \%$ of patients. There is thus a clear cytological distinction between the staining characteristics of the cellular component in liquor amnii collected after the 30th week of gestation.

The colour changes seen in the cytoplasm of cells obtained with Shorr's stain were compared with

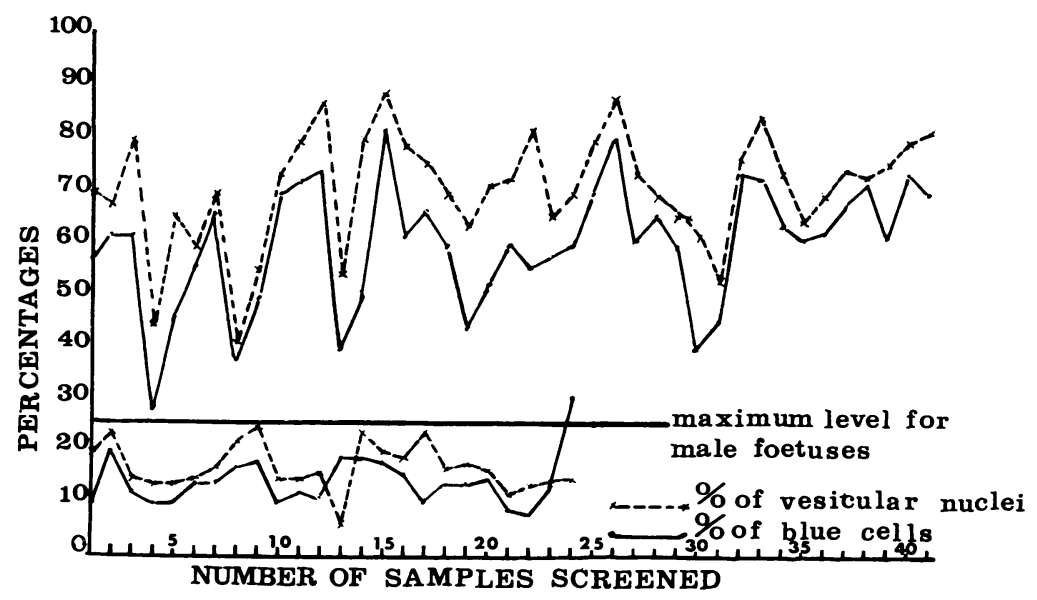

Fig 7 Proportion of anucleate/ pyknotic nuclei to vesicular nuclei (Papanicolaou's stain) and the proportion of red to blue cells (Shorr's stain) from the desquamated cells in 66 samples of liquor amnii collected after 32 weeks. There is a clear distinction between the cells desquamated from male and female foetuses. 
nuclear differences seen using Papanicolaou's staining technique. In the latter method the proportion of anucleate/pyknotic cells was compared to the proportion of vesicular cells (fig 7).

In male foetuses the maximum percentages of vesicular nuclei did not exceed $24 \%$. In female foetuses 40 out of 42 patients $(95 \%)$ had more than $50 \%$ vesicular nuclei.

There was a close correlation between prenatal sex determination by both techniques but the proportion of vesicular nuclei seen using the Papanicolaou method was higher in both girls and boys (fig 7). However, when both methods are used together after 30 weeks' gestation prenatal sex determination is very accurate.

\section{Discussion}

Prenatal diagnosis of foetal sex is valuable when sex-linked disorders are suspected. In the mid trimester of pregnancy accurate sexual differentiation can be made from the presence of female sex chromatin in the nucleus of cells found in liquor amnii (Barr and Bertram, 1949), by fluorescent microscopy looking for the $\mathrm{Y}$ chromosome, and by chromosome culture. However, a sufficient number of unimpaired nuclei are not always found and chromosome culture is a time-consuming process requiring special facilities. Even under the best conditions foetal cells will grow in tissue cultures in only about $85 \%$ of cases. The cytological method described above using the Shorr's stain is very simple and results can be available within minutes. Nevertheless occasional discrepancies with the method do occur and in the above series one girl was predicted who ultimately proved to be a boy. When, however, the proportion of anucleate/pyknotic cells to vesicular cells was counted the correct sex was predicted in all cases.

By combining the two techniques a completely accurate prediction was obtained with very little extra time consumed.

At present the technique is accurate only after the 30th week of gestation. This is because the method depends on desquamation of vaginal cells in the liquor. The vagina is a solid rod in early gestation (Hamilton, Boyd, and Mossman, 1972) so that cellular desquamation is impossible. However, samples of liquor in the mid trimester are not readily available in sufficient numbers to determine the accuracy of the method, but this important point needs to be examined further.

An additional difficulty could arise in the presence of a twin pregnancy. The problem can be eradicated if ultrasonic examination is performed before amniocentesis. This has the additional advantage of allowing placental localization.

Differential cell counts of liquor have been described to estimate gestational age (Bishop and Corson, 1968; Mandelbaum and Evans, 1969; Husain and Sinclair, 1971) but the method is less accurate if foetal sex is not simultaneously determined. Thus Bennett et al (1972) noted that at 32 weeks female infants were assigned a gestational age in advance of the known duration of pregnancy by three weeks.

A combination of differential cell counts and sexual determination using both the colour differences (Shorr's stain) and the proportion of vesicular nuclei could permit more accurate assessment of the true length of gestation.

We wish to thank the resident medical and nursing staff of the Maternity Unit, Watford General Hospital, for their willing cooperation in collecting samples of liquor.

We also thank Mrs Sylvia Hall for secretarial assistance, and $\mathrm{Mr} \mathrm{M}$. Sale and $\mathrm{Mr} \mathrm{H}$. Grimston for the photographs.

\section{References}

Arendzen, J. H., and Huisjes, H. J. (1971). A simple method for prenatal determination of sex. Acta cytol., 15, 316-317.

Barr, M. L., and Bertram, E. G. (1949). A morphological distinction between neurones of the male and female, and the behaviour of the nucleolar satellite during accelerated nucleoprotein synthesis. Nature (Lond.), 163, 676-677.

Bennett M. J., Morris, H. H. B., and Davey, D. A. (1972). The influence of fetal sex upon liquor cytology as a means of estimating gestational age. J. Obstet. Gynaec. Brit. Cmwlth, 79, 340-343.

Bishop, E. H., and Corson, S. (1968). Estimation of fetal maturity by cytologic examination of amniotic fluid. Amer. J. Obstet. Gynec., 102, 654-664.

Hamilton, W. J., Boyd, J. D., and Mossman, H. W. (1972). Human Embryology, 4th ed., p. 408. Heffer, Cambridge.

Huisjes, H. J. (1968). Amniotic Fluid Cytology, pp. 33-35. Van Gorcum, Assen, The Netherlands.

Husain, O. A. N., and Sinclair, L. (1971). Estimation of maturity in the foetus and newborn. Proc. roy. Soc. Med., 64, 1213-1217.

Mandelbaum, B., and Evans, T. N. (1969). Life in the amniotic fluid. Amer. J. Obstet. Gynec., 104, 365-377.

Rosa, P. A., and Fanard, A. E. (1951). A new method of prenatal diagnosis of sex. Int. J. Sexol., 4, 160-163. 